\title{
COZinetSSE
}

\section{РАСПРЕДЕЛЕННАЯ ВОЗОБНОВЛЯЕМАЯ ЭНЕРГЕТИКА. ВКЛАД «ZEINET\&SSE» В «ЗЕЛЕНУЮ» ЭКОНОМИКУ КАЗАХСТАНА}

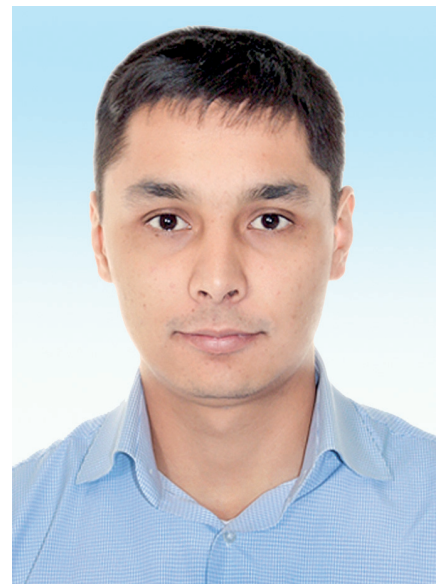

Д.М. КУЛТАЕВ, ведущий инженер программист

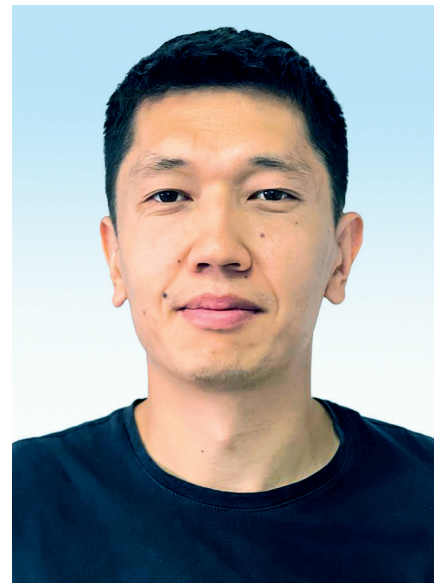

М.А. МЕЙМАНОВ, инженер программист 2 категории

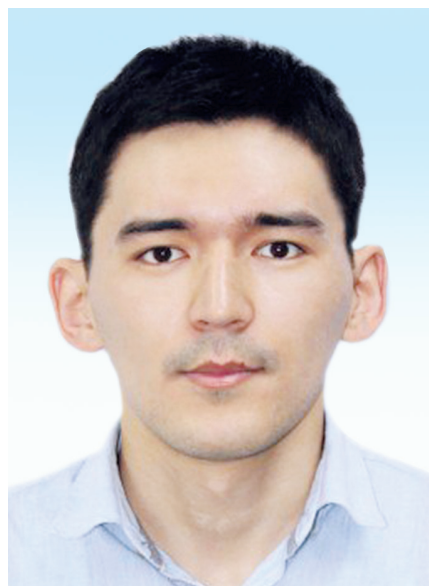

Б.С. ДОСАНОВ, разработчик ПО

TOO «ZEINET\&SSE»,

Республика Казахстан, 050001, г. Алматы, пр. Раимбека 348A ефтяные компании сталкиваются с растущим давлением со стороны акционеров и активистов, которые вынуждают их отказаться от ископаемого топлива и инвестировать в возобновляемые источники энергии. Международное энергетическое агентство (МЭА) заявило, что компании должны прекратить разведку месторождений нефти и газа. МЭА обосновало это не только предотвращением климатической катастрофы, но и тем, что дополнительные энергоресурсы попросту не найдут спроса. Например, 26 мая Гаагский окружной суд обязал Royal Dutch Shell сократить свои выбросы углекислого газа $\left(\mathrm{CO}_{2}\right)$ на 45\% к 2030 году по сравнению с уровнем 2019 года. Речь идет о выбросах не только от деятельности компании, но и от энергетических продуктов, которые она продает. Так же акционеры Chevron на годовом собрании с помощью голосования определяли цели компании по сокращению выбросов [1].

Давление на компании, работающие с ископаемым топливом, оказывают не только акционеры, но и банки. Крупнейшие кредитные организации мира в последнее время стали поддерживать движение к низкоуглеродному будущему [1]. В 2021 году впервые с момента заключения Парижского соглашения об изменении

\footnotetext{
* Адрес для переписки. E-mail: info@zeinetsse.com
} 


\section{ВОЗОБНОВЛЯЕМАЯ ЭНЕРГЕТИКА}

климата темпы кредитования ведущими мировыми банками «зеленой» энергетики превысили финансирование проектов на ископаемом топливе.

Распределенная возобновляемая энергия (DRE-decentralized/distributed renewable energy) является наиболее перспективной моделью для обеспечения устойчивой энергетики. Возобновляемые и распределенные ресурсы, такие как небольшие солнечные и ветряные электростанции более экологичны, поскольку используют возобновляемые источники энергии, что приводит к меньшему воздействию на окружающую среду по сравнению с различными процессами добычи, преобразования и распределения ископаемого топлива. Кроме того, при их использовании выбросы парниковых газов значительно снижаются.

Распределенная возобновляемая энергия является быстрым и дешевым решением по сравнению со строительством больших централизованных электростанций и высоковольтных линий электропередач [2]. На сегодняшний день мы наблюдаем определение выбора в сторону концепции распределенной/децентрализованной возобновляемой энергетики на мировом рынке.

История показывает, что стимулами централизованных энергосетей было повышение КПД агрегата, уменьшение материалоемкости и стоимости. Такой подход оптимален в случае с крупными потребителями - фабрики, заводы, города, где потребление энергии изначально большое. В случае с множеством распределенных на большой территории, где выигрыш в агрегатном КПД теряется в транспортных потерях в энергосетях наблюдается смещение в сторону децентрализованных энергосетей. Кроме того, централизованные и не возобновляемые системы, а именно крупномасштабные установки, использующие ископаемое топливо - уголь и газ, являются экологически неустойчивыми, поскольку основаны на истощении ресурсов.

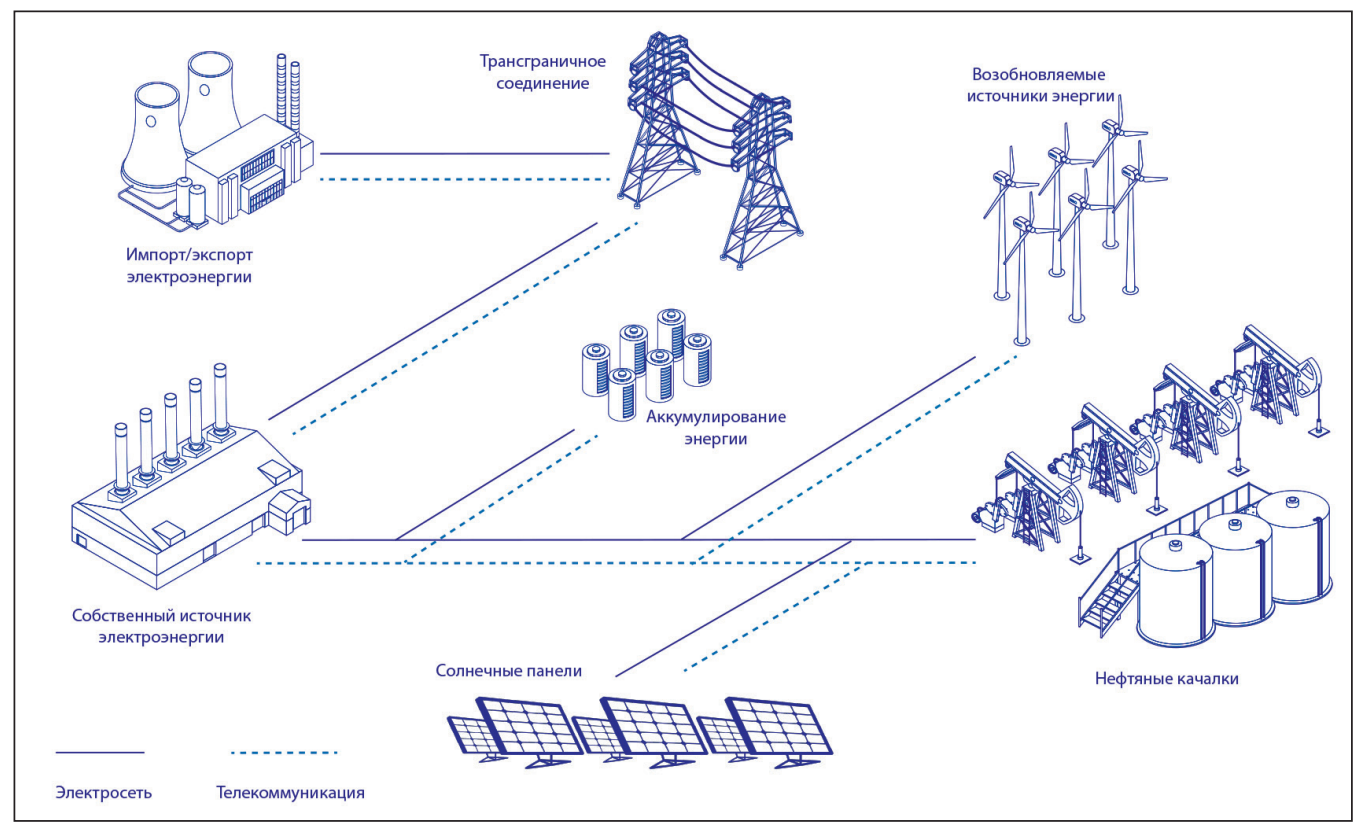

Рисунок 1 - Децентрализованная энергетическая сеть 
Концепция внедрения децентрализованных источников не означает отказ от централизованного энергоснабжения, однако предполагает, что им имеется обоснованная альтернатива. Небольшие автономные электростанции хорошо согласуются с использованием местных источников энергии, как ветер солнце, вода.

Такие установки, обладая, небольшой мощностью, обеспечивают использование энергии на месте ее производства, исключая необходимость создания энергосетей, а система DRE позволит излишки отдать в основную сеть и позволит создавать корректные прогнозы по потреблению и производству.

Также, важным элементом в DRE являются накопители энергии в виде аккумуляторов, которые способствуют развитию локальной электросети (микросеть) и позволяют работать в автономном режиме в случае разрыва соединения с общей сетью [3]. Поэтому в удаленных местностях установка солнечных и ветровых электростанций вместе с аккумуляторами соответствующей мощностью являются самым практичным и экономичным вариантом для обеспечения потребителей необходимой электроэнергией полностью отключившись от электросетей.

Возобновляемые источники - это новый политический курс Казахстана и закон «О поддержке возобновляемых источников энергии», принятый еще в 2009 г., оказывает поддержку в становлении данного сектора. Стоит отметить, что наша страна по своему географическому положению находится в ветровом поясе северного полушария и на значительной территории страны наблюдается достаточно сильные воздушные течения в основном Северо-Восточного и Юго-Западного направления. По оценкам экспертов, среднегодовая скорость ветра составляет порядка 6 м/с и выше и ветрогенераторный потенциал оценивается примерно в 1820 млр кВтч. Если говорить о солнечной энергетике, то годовая длительность солнечного света составляет 2200-3000 ч/год, приблизительная оценка по мощности - 1300 - 1800 кВт

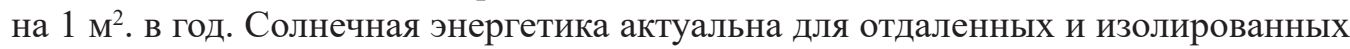
регионов нашей страны [4].

Международные организации, такие как проект развития ООН (ПРООН), активно поддерживают Казахстан в секторе «зеленой» экономики в рамках проекта «Зеленый мост» и активно оказывают финансовую помощь в проектах по ВИЭ. Международное агентство по возобновляемой энергетике (IRENA) продвигает рыночный механизм аукционных торгов по отбору проектов «зеленой энергетике» в Казахстане [6].

В 2019 году совместно с Правительством РК ПРООН и финансовой поддержке экологического фонда ТОО «РФЦ по поддержке Возобновляемых Источников Энергии» и АО «КОРЭМ» был проведен один из первых аукционов с уже разработанной технической документацией на строительство солнечной электростанции мощностью 50 МВт в поселке Шаульдер в Туркестанской области.

В реализации указанного проекта Шаульдер компания «Zeinet\&SSE» внедряет лучшие локальные решения по автоматизации промышленного объекта на базе своего накопленного опыта в энергетике, аналитике, обработке и передаче данных.

В рамках концепции по переходу Казахстана к «зеленой» энергетике в 2020 году в Актюбинской области была запущена ветряная электростанция под поселком «Бадамша» общей мощностью 48 МВт. 13 ветро-турбинных генераторов ежегодно обеспечивают регион электроэнергией в объеме 198 ГВтч [7]. 


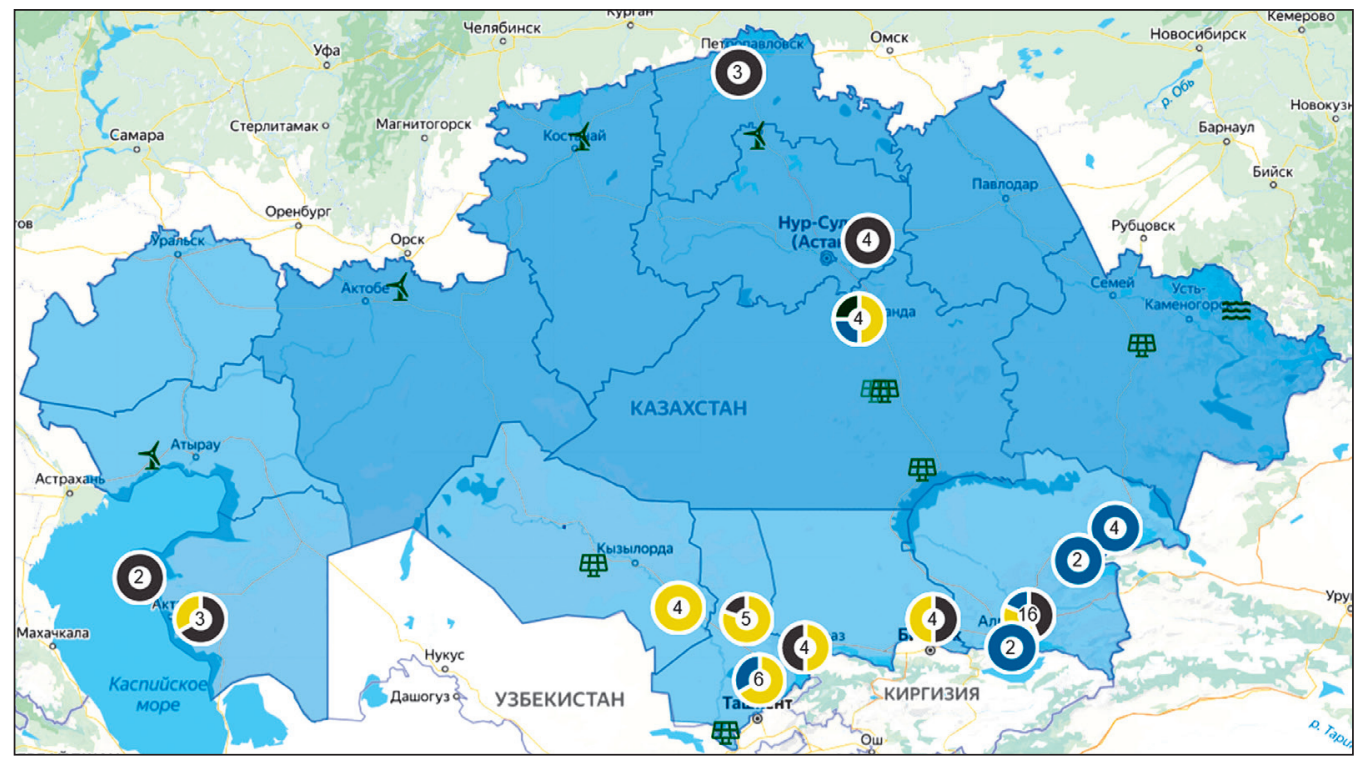

Рисунок 2 - Карта объектов ВИЭ [5]

В рамках первой фазы по внедрению АСУ ТП (Автоматизированная система управления технологическим процессом) на ВЭС «Бадамша» в компании была разработана SCADA (Система автоматического контроля и сбора информации) и система ПАЗ (Противоаварийная защита) на базе программно-технического комплекса Simatic S7 производства Siemens в полном соответствии с европейскими требованиями. На сегодняшний день «Zeinet\&SSE» активно ведет работы по запуску второй фазы проекта «Бадамша».

В рамках Государственной программы «Цифровой Казахстан» национальный оператор KEGOC активно занимается внедрением технологии «умные сети». Одним из ключевых проектов является внедрение системы АРЧМ (автоматическое регулирование частоты и мощности). «Zeinet\&SSE» разрабатывает специальное решение на базе цифровых технологий для подключения электростанции в систему АРЧМ. Этот проект является мостом к возобновляемым источникам энергии, так как АРЧМ автоматически компенсирует нестабильность ВИЭ [8].

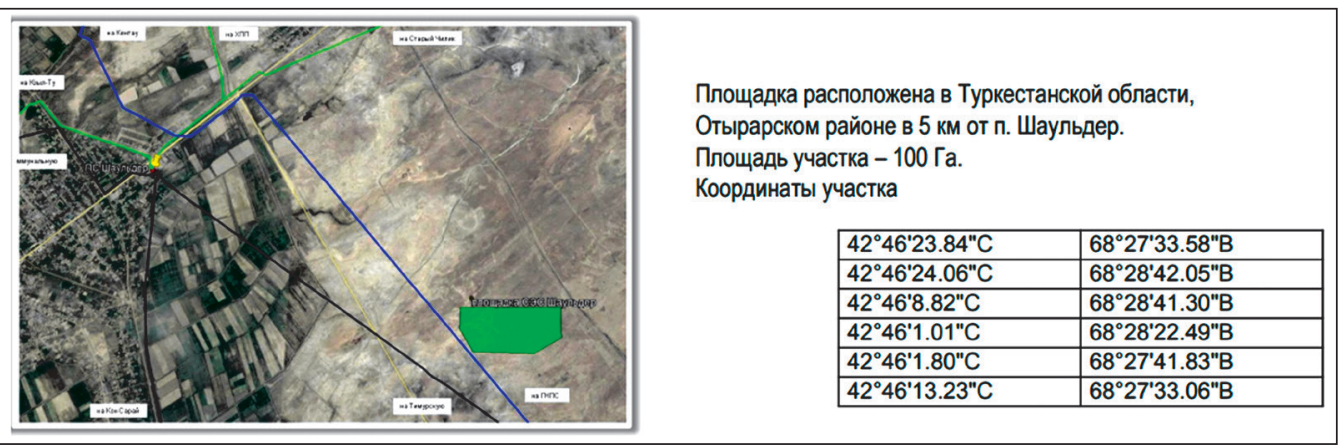

Рисунок 4 - СЭС Шаульдер 
Перед Казахстаном стоит амбициозная задача довести долю возобновляемых источников энергии до $50 \%$ к 2050 году. Согласно законодательству РК проекты ВИЭ входят в перечень приоритетных инвестиционных проектов. Для стимулирования «зеленой» энергетики в 2020 году к инвестиционным преференциям были добавлены следующие пункты: освобождение от имущественного налога; освобождение от земельного налога; освобождение от КПН. Также увеличивается срок контракта на гарантированный выкуп электроэнергии Оператором ВИЭ до 20 лет.

Подводя итоги, можно отме-

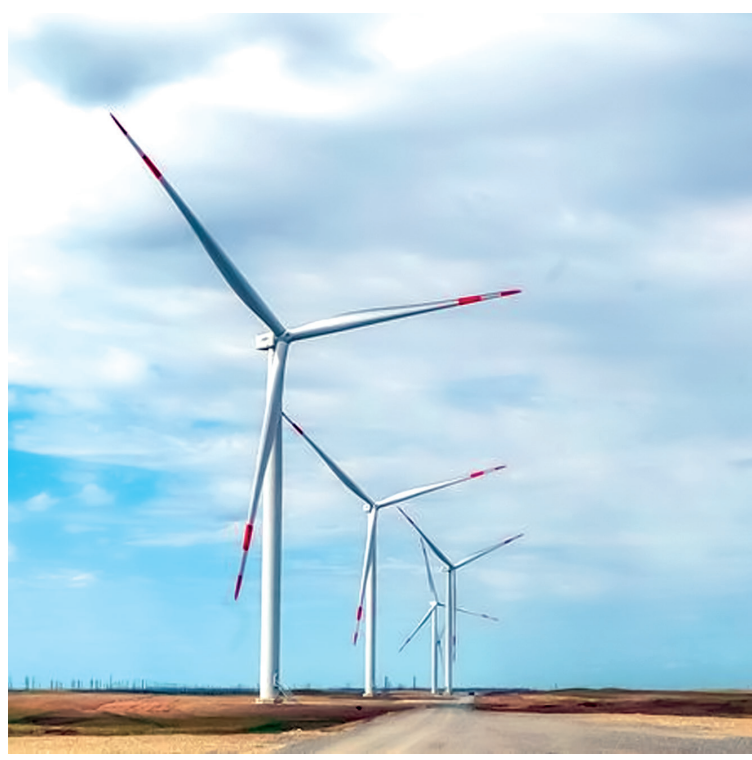

Рисунок 5 - ВЭС Бадамша тить, что у Казахстана большой потенциал в области энергетики, использующий ископаемое топливо. Однако, учитывая современные тенденции и проблемы глобального потепления, государство постепенно меняет свой вектор в сторону возобновляемых источников энергии. В связи с чем, распределенная возобновляемая энергетика будет набирать все большую актуальность для устойчивого развития будущего страны.

\section{ИНТЕРНЕТ-ИСТОЧНИКИ}

1 «Shell - не последняя». Суд впервые обязал компанию снизить выбросы: почему это важно? / https://thebell.io/shell-ne-poslednyaya-sud-vpervye-obyazal-kompaniyusnizit-vybrosy-pochemu-eto-vazhno

2 Distributed Energy Resources (DER) / https://www.wbdg.org/resources/distributed-energyresources-der

3 Using Distributed Energy Resources A How-To Guide for Federal Facility Managers / https://www.nrel.gov/docs/fy02osti/31570.pdf

4 Казахстанская международная выставка энергетики, электрооборудования и машиностроения / https://www.powerexpo.kz/en/

5 Расчетно-финансовый центр по поддержке ВИЭ / https://rfc.kegoc.kz/vie/yamaps

6 Соглашение о софинансировании между программой развития организации объединенных наций и Министерством энергетики Республики Казахстан / https://adilet. zan.kz/rus/docs/O1500000002

7 Ассоциация нефтесервисных компаний Казахстана / https://www.kazservice.kz/en/ info/news/eni-s-p-a-we-create-energy/

8 Сколько инвестиций привлечено в сектор возобновляемой энергетики Казахстана / https://forbes.kz/news/2021/02/09/newsid_243566 